Marko Grubačić

UDC: $316.77: 004.55$

Ljiljana Marković

UDC: $316.7(520)$

Univerzitet u Beogradu

DOI: $10.18485 /$ dh.2015.1.ch2

Filološki fakultet

\title{
NASTANAK I RAZVOJ VIŠEMEDIJSKE I DIGITALNE UMETNOSTI U JAPANU
}

\begin{abstract}
Sažetak
Pojava inteneta je nesumnjivo doprinela demokratizaciji i pluralizmu umetničkih izraza. Ovaj sveprisutni, svuda dostupni "virtuelni muzej” iznedrio je i jednu novu, međunarodno priznatu generaciju japanskih umetnika koja uspešno stvara umetnička dela na raskršću softverskog inženjerstva, dizajna i umetnosti. Nikoga ne može iznenaditi činjenica da su vizuelne umetnosti odavno prestale da egzistiraju u eksluzivnom domenu akademskih, tradicionalno obrazovanih likovnih stvaralaca. Štaviše, čini se da se poznavanje računarskih programskih jezika i informaciona pismenost danas nameću kao osnovni preduslov za uspešno stvaranje i razumevanje tehnološki inspirisane umetnosti. Sa druge strane, u galimatijasu vizuelnih informacija sve teže prepoznajemo trajni i suštinski kvalitet umetničkih dela. Razmatranje okolnosti koje su doprinele nastanku i razvoju višemedijske i digitalne umetničke scene u Japanu - svojevrsnom tehnološkom raju u kojem granične umetničke prakse nalaze izuzetno plodno tle - može poslužiti kao putokaz ka dubljem razumevanju sadašnjih i budućih dometa stvaralaštva na raskršću umetnosti i tehnologije na globalnom nivou.
\end{abstract}

Ključne reči: japanska kultura, digitalna i višemedijska umetnost, umetnost i tehnologija

U razgovoru o posleratnoj umetničkoj sceni Japana, treba naglasiti njenu osnovnu odliku - izraziti pluralizam koji je u drugom kontekstu označen i kao „postavangardistički“. Intenzivna razmena ideja slikara, muzičara i režisera stvorila je pritom osobenu simbiozu - zasebne medije, pokretne galerije, unikatne sveske sa grafikama, provokativne plakate, „svojeručne manifeste“, kolaže, performanse, nezavisnu filmsku produkciju, konceptualnu fotografiju, kinetičke objekte i mnogo toga drugog. Na 
umetničkoj sceni su otkrivani novi pristupi stvarnosti, bukvalno inscenirajući sugestivne „događaje” što bude neočekivane emocije. I kao što je literatura inicirala nov, neočekivan uvid i pogled na stvari - od knjige s praznim, neispisanim stranicama do knjige s obiljem znakova i sličica - tako su se i u drugim umetnostima, tačnije u njihovom amalgamu, mogli naći začuđujući spojevi: seriozni i blasfemni, filosofski i neozbiljni, subverzivni i bezazleni, komični i zastrašujući. Povreda estetskih pravila je namerno ogoljena da bi omela uživanje u pomatranju. Tematizujući otpor, usamljenost i strah, sa povikom „Podzemlje je nadgradnja!“, sugestivna „oluja predmeta i slika" svesno je uskratila smislene poruke u nameri da naizgled besmislene instalacije i objekte $u$ „performativnom prostoru“ predstavi kao „dokazni materijal“ sa poprišta psihe.

Tokom izuzetno burnih šezdesetih godina, japanska umetnost bila je u znaku dva značajna pokreta. Junk-art tendencija anti-umetnosti (han-geiđucu) je bila delimično podstaknuta zanosom političkih protesta. Druga tendencija je bila „ne-umetnost” (hi-geiđucu) koja se nastavila u sledećoj dekadi. ${ }^{1}$ Obe su bile toliko jake da su označile seizmičku promenu paradigme, preobražaj lica japanske umetnosti i same prirode avangarde. Ova promena je u nekim slučajevima čak i prethodila procesu "dematerijalizacije" i defetišizacije umetničkog objekta koji se odvijao na globalnom planu šezdesetih godina. Davno pre pojave postmodernog diskursa, 1963, ovu transformaciju je, naime, naslutio i teorijski formulisao kritičar Mijakava Acuši u svojoj diskusiji o umetnosti nakon enformela. Označio je kao smenu modernog (kindai) i dolazak savremenog (gendai). ${ }^{2}$

Pojmom han-geiđucu označene su tendencije koje teže da obnove fundamentalnu strukturu "stvarnog" unoseći u nju sasvim neočekivane gradivne sastojke: svakodnevne predmete, znakove i vulgarne slike. Unošenjem svakodnevnih predmeta u kontekst estetskog, umetnost je svrgnuta. Skinuta je s pijedestala nedodirljivosti. Ipak, ovaj "silazak u svakodnevicu” kao ciljana „degradacija“ umetnosti ima, razume se, samo metaforički smisao, s obzirom da se ona odvijala u kontekstu umetno-

1 Reiko Tomii, After the 'Descent to the Everyday: Japanese Collectivism from Hi Red Center to The Play, 1964-1973, in: Collectivism After Modernism: The Art of Social Imagination after 1945, ed. Blake Stimson (Minneapolis, MN, USA: University of Minnesota Press, 2007), 51. Doryun Chong, ed. From Postwar to Postmodern: Art in Japan 1945-1989 : Primary Documents (New York: Museum of Modern Art, 2012), 105. 
sti. Kako je na drugom mestu jezgrovito formulisao Birger, "Praksa koja je nameravala da ima izvan-umetnički efekat, pretvorila se u praksu inherentnu samoj instituciji umetnosti". ${ }^{3}$ Bilo je, međutim, i takvih radikalnih umetničkih kolektiva poput Hi Red Centra, koji su dramatično proširili kontekst umetnosti, preobražavajući, s naglaskom na provakativnosti i buntovništvu, svakodnevni život u umetnost - izvodeći performanse u realnim, svakodnevnim životnim prostorima. Sredinom šezdesetih, razvoj ekperimentalne umetničke prakse doveo je do nastanka koncepta ne-umetnosti ( hi-geiđucu) i pojave Mono-ha ("Škole stvari"), gde naglasak više nije bio na stvaranju u tradicionalnom smislu (cukuru koto), već na ne-stvaranju (cukuranai koto). Ova ne-umetnost je, naime, odbacivala čak i anti-umetničku pobunu protiv stvaranja.

Uopšte uzev, mogu se prepoznati tri faze u prelasku iz modernog (kindai) u savremeno (gendai). U prvoj fazi, od sredine do kraja pedesetih, ističu se rane Điken kobo ("Eksperimentalna radionica"), čiji su se intermedijalni eksperimenti oslanjali na nasleđe evropske "totalne umetnosti" Bauhausa i najavili pojavu tehnološki orijentisane umetnosti krajem naredne decenije. Van svake sumnje, mnoga značajna dela grupe Điken kobo nastala su u sklopu snažnog zamaha industrijalizacije i modernizacije u posleratnom Japanu, pa nas ne sme iznenaditi što je upravo ova grupa bila jedna od prvih avangardnih skupina koje su nastojale da spoje umetnost i tehnologiju. Kada se, 1953, na tržištu pojavio automatski slajd projektor, umetnici kolektiva Điken kobo su organizovali niz projekcija u kojima su vešto uskladili ritam slike i zvuka - muzike i glasa - u nameri da dinamizuju kolektivno iskustvo publike u recepciji umetničkog dela. Upečatljive auto-slajd projekcije nudile su različite poglede na grupu predmeta, najčešće providnih, koji su se automatski smenjivali u skladu sa karbonskim oznakama na usnimljenoj audio-traci. Gledajući s istorijske distance, ove auto-slajd prezentacije, sačinjene od fotografija, muzike i naracije - koje su i sami pripadnici grupe nazivali "prezentacijama" (hapjokai) - predstavljale su izuzetno originalan koncept, koji dopire do krajnjih žanrovskih granica književnosti, kinematografije i nepokretnih slika.

Umetnost performansa nije, naime, još ni zaživela na internacionalnoj sceni u trenutku kada su pripadnici pokreta Gutai iz regije Kansai,

3 Peter Bürger, "Avant-Garde and Neo-Avant-Garde: An Attempt to Answer Certain Critics of Theory of the Avant-Garde," in: New Literary History 41 (Autumn 2010): 695-715. 
1955. godine, započeli prve eksperimente u oblasti akcione i tzv. site-specific umetnosti. Prva velika izložba grupe Gutai održana je u borovoj šumi kraj reke Ašija u prefekturi Hjogo iste godine. Jošihara Điro je, kao organizator ove izložbe i vođa pokreta, umetnicima dao zadatak da načine radove koji nisu ograničeni veličinom izložbenog prostora, koji mogu biti izloženi bez zidova, mogu kisnuti, izdržati nalete vetra, biti podložni dodirima, igri, i koji mogu biti vidljivi u mraku. Umetnici su odgovorili smelim interakcijama sa prirodnim okruženjem, koje su podrazumevale, na primer, kačenje providnih kesa napunjenih obojenom vodom na grane drveća, ali i svetlosne eksperimente i sečenje kedrovih stabala sekirom. Nepuna tri meseca kasnije, predstavili su se i tokijskoj publici, naišavši na potpuno nerazumevanje kritike. Tako je, na primer, Širaga Kazuo - u performansu pod imenom „Izazivanje blata“ (Doro ni idomu) - u belim bokserskim gaćama uronio u blato, rveći se sa njim. Murakami Saburo (1925-1996) je probadao poređana platna natron papira u radu koji je nazvan „Šest rupa" (Mucu no ana), demonstrajući napad na dvodimenzionalnu prirodu slikarske površine i uvodeći naročitu dimenziju prostora i vremena u slikarsku praksu. Ovo probijanje papira (Kami jaburi) bilo je praktikovano i tokom manifestacije "Gutai umetnost na sceni“ (Butai o šijo suru Gutai biđucu) u Osaki 1957. godine, jednom projektu koji će biti zabeležen kao prva umetnička izložba održana na sceni. Širaga i dvojica drugih izvođača su tom prilikom hodali scenom obučeni u dve verzije "Električne odeće“ (Denki fuku) umetnice Tanaka Acuko (1932-2005), napravljene od treperećih sijalica u boji i mnoštva električnih kablova.

lako je pokret Gutai ostao poznat po ovim revolucionarnim performansima i izvedbenim inovacijama, zanimljivo je da su oni sebe pre svega smatrali slikarima. Širaga, Murakami, Tanaka i ostali razvijali su do kraja svojih nekonvencionalnih karijera jedan poseban i "nezavisan“ slikarski jezik. Podsećanja radi, treba pomenuti da je Širaga, koji se školovao kao nihonga slikar i budistički sveštenik, slikao stavljajući stopala na platno položeno na pod, da bi zatim koristio i celo telo u slikanju koje se odvija tokom rvanja u blatu. Tanaka je, nalazeći inspiraciju u dečijoj kreativnosti, napravila seriju crteža i slika izvedenih iz svoje "Električne haljine“. U radu nazvanom "Naslikano bacanjem lopte“ (Tokju kaiga, 1954), Murakami Saburo je, opet, bacivši gumenu loptu namočeno u mastilo na platno, 
zabeležio otisak predmeta u pokretu. Time je, na izvestan način, naslutio kasnija istraživanja tela kao objekta koji probija papirnu površinu.

Ima još neobičnijih primera. Šimamoto Šozo (1928-2013) je pucao u posude sa bojom iz pištolja i lomio flaše boje o kamenje naslagano na platnu, istraživajući granice kreacije i destrukcije. Kanajama Akira (Kanayama Akira, 1924-2006) je, šaleći se da je previše zauzet da bi sam slikao, koristio automatski automobil-igračku u naizgled razigranoj, a zapravo ozbiljno zamišljenoj kritici Polokovog „gestualnog“ slikanja kapanjem boje. Bilo je, naravno, članova grupe koji su bili više posvećeni polju umetničkog delovanja koji danas nazivamo umetnost instalacije. Motonaga Sadamasa je prilikom prve Gutai izložbe predstavio rad pod nazivom Rad (voda) (Sakuhin [mizu]). Napunivši plastične vreće u obliku suza drečavo obojenom vodom, obesio ih je iznad jarko obojenog kamenja, izlažući ih pored dvodimenzionalnih slika i ostataka akcionih radova svojih kolega. U svojim „interdisciplinarnim“ delima i instalacijama, često je koristio vodu, dim i vinil.

Druga faza prelaska iz modernog u savremeno, započela je krajem pedesetih, kada su kolektivi i pojedinci u okviru anti-umetničkih tendencija ugrađivali otpad i predmete za svakodnevnu upotrebu u umetnička dela, iskoristivši prostor koji im je otvorila umetnost enformela. U opisu ovih dela često se koristio francuski termin objet (japanski izgovor: "obuđe"), označavajući umetničku formu sličnu američkom proto-pop-kombajnu i asamblažu. Stvarajući objet, buntovnici tzv. Jomiuri anpan generacije hteli su da sabotiraju umetnički sistem, tvrdoglavo odbijajući da se povinuju tradicionalnim definicijama umetnosti i drsko rušeći utvrđene granice između umetnosti i života. $U$ tome su se najviše isticale grupe Kjušu-ha, Neo-Dada, Grupa Ongaku (“Muzika”), Hi Red Center i Đikan-ha ("Škola vremena").

Premda je, uprkos neospornim zaslugama, zauzela malo prostora u kritičkim osvrtima na posleratnu umetnost, Kjušu-ha se može smatrati najinovativnijom i najradikalnijom umetničkom grupom u periodu nakon II svetskog rata. Nju je u Fukuoki 1957. godine osnovalo patnaestak slikara i vajara, čiji je ideolog bio Kikuhata Mokuma. Pripadnici pokreta Kjušu-ha su osuđivali „endemsko“ siromaštvo zemljoradnika i rudara na ostrvu Kjušu u vreme kada su gradovi na glavnom japanskom ostrvu Honšu prosperirali. Od oko hiljadu radova koje su članovi grupe stvorili u prvim godinama 
postojanja, ostalo je sačuvano jedva devedesetak, što u dobroj meri onemogućava podrobniju analizu u sklopu savremene japanske umetnosti. Nezavisno od toga, značaj ove energične grupe treba pre svega treba tražiti u njihovom odnosu prema društvenoj realnosti u neposrednoj lokalnoj sredini. Razvijajući jedinstveni antimodernistički umetnički jezik u provincijskoj izolovanosti - na način sasvim različit od pripadnika grupe Gutai ili umetnika iz regije Kanto, sa egzaltiranim patosom za koji se mislilo da je bio moguć samo na početku stoleća - kroz stvaralačke odzive pripadnika Kjušu-ha moćno odzvanja antagonistički stav prema dominaciji tokijskog umetničkog establišmenta.

Umetnici grupe Kjušu-ha koristili su karton, vinil, gumu i asfalt, koji simbolično ukazuju na njihovo poreklo i vezu sa rudarskom zajednicom i udaljenost od velikih saobraćajnih infrastrukturnih projekata. Vremenom su njihovi radovi sve više ličili na totemske strukture sastavljene od otpada - odbačenih guma, polomljenih delova metalnih sprava, starih bicikala i gomila opušaka od cigareta. Dobar primer njihove ekstremne upotrebe materijala - na tragu rušenja konvencionalnog poimanja umetnosti - bio je i rad priložen za izložbu „Jomiuri anpan“ (Yomiuri andepandan) u Tokiju 1958. godine, koji se satojao od đubreta umotanog u slamnate strunjače (tatami). Ovakvi radovi, vesnici nove anti-umetnisti i tzv. junk-art-a, ukazivali su na slikovit način na probleme potrošačkog kapitalizma koji maskira stvarne probleme života u provinciji, razlikujući se istovremeno - fundamentalno - od pop-arta u kome se se koriste fino obrađeni industrijski proizvodi.

Kikuhata Mokuma, vođa škole Kjušu-ha, bio je posebno izričit u svojim antikapitalističkim stavovima, smatrajući da je u savremenom Japanu individualizam inficirao društvo poput zaraze, potpomognut delovanjem medija i kapitalističkim uređenjem. Umetnost je, smatrao je Kikuhata, pobegla od politike, odnosno odbacila humanizam. U neprekidnoj potrazi za novim etičkim stavom koji bi vratio humanizam u okrilje umetnosti, Kikuhata je došao do pojma materijalnosti, odnosno do povezivanja materijalnosti sa svakodnevnim životom. Smatrajući da utvare stupaju na mesto stvari, da je konvencionalno slikarstvo prevara, kamuflaža, falsifikovanje stvarnosti, Kikuhata je novu kreativnost tražio u „svakidašnjem“. Pokušavajući da naglasi lokalno, koristio je materijale poput kovanica, zuba, veštačkih očiju, ramova, drvene građe. 
Međutim, ipak treba istaći da je Tokio šezdesetih godina bio centar antimodernističkih i političkih aktivnosti. U njima je uzela učešće i grupa nadarenih avangardnih umetnika koji su osnovu svoje umetnosti tražili u svakodnevnom. Nadenuvši sebi ime Neo-Dada Organizator[i], svoju ideologiju su zasnivali na tradiciji predratnog evropskog radikalizma. Moćni eho dadaističkog pokreta, nastalog u Cirihu tokom I svetskog rata, odjekivao je Parizom dvadesetih, Nju Jorkom pedesetih, ali i Tokijom šezdesetih godina. Pitanja koja je postavila evropska Dada, a pre svega Marsel Dišan, taj miljenik predratne avangarde koji je prvi postavio svakodnevne „redimejd“ predmete na umetnički postament, opsedala su i novu generaciju japanske avangarde - gde se zapravo nalazi granica između umetnosti i života?

„Neo-Dada Organizatore“ (Neo Dadaizumu Oruganaizā[zu]) sačinjavala je grupa od desetak avangardnih umetnika koji su se okupljali u „Beloj kući“ (Hovaito hausu), prebivalištu Jošimura Masanobua (1932-). Dok je neke od njih interesovala dadaistička i nadrealistička estetika, drugi su bili posvećeni uličnim demonstracijama i izložbama za koje bi se reklo da su isključivo bile namenjene privlačenju pažnje javnosti. Među najistaknutijim članovima grupe bili su Jošimura Masanobu, Ušio Šinohara (1933-), Šusaku Arakava (1936-), Kazakura Šo (1936-) i Akasegava Genpei (1937-2014), koji će kasnije osnovati Hi Red Center. Neodadaistička strategija medijskog spektakla najslikovitije se u ogledala u delovanju Ušio Šinohare, koji je svojim neuračunljivim ponašanjem i imidžom buntovnika sa „mohikan“ frizurom redovno privlačio pažnju medija (koje su ga nazivali rokabiri saka - „rokabili umetnik“). Neizbrisiv uticaj ostavila je na njega prezentacija francuskog enformel slikara Žorža Matjea u jednoj tokijskoj robnoj kući 1957. godine, kada je Šinohara naslutio efekte „akcionog slikanja" u javnom prostoru, odnosno medijske pažnje koju takva praksa prati. Šinohara je pod uticajem Matjea započeo seriju tzv. Bokserskih slika (Bokušingu peintingu), koje je izrađivao tako što je bokserske rukavice, zamotane u krpe, umakao u mešavinu sumi mastila i pirinčanog lepka, da bi zatim bokserskim udarcima nanosio mrlje boje na površinu improvizovanog platna Ova potpuna usmerenost na demonstraciju slikarskog procesa pratila je i neobična nezainteresovanost - svojevrsna „nebriga“ za krajnji rezultat - mnogi njegovi radovi nisu nadživeli prezentacije i uništavani su na licu mesta. Za Šinoharu je trenutni publicitet bio jedina nagrada. On 
je žudeo za priznanjem medija zato što je odbacivao uzvišeni modernistički ideal umetnosti radi umetnosti, verujući da je akcija sama po sebi značajnija od završene slike kao zaokruženog i „zatvorenog dela“ u smislu Umberta Eka. Međutim, takođe je bio svestan činjenice da, poput drugih avangardnih umetnika, ne može da računa na finansijsku dobit. Neumereni vapaj za medijskom pažnjom Ušio Šinohare i drugih umetnika Neo Dade imao je pritom i svoju negativnu stranu - sve do nedavno njihovi medijski ispadi bili su okarakterisani kao mladalačka indiskrecija koja ne zavređuje pažnju i ozbiljniji osvrt likovnih kritičara i istoričara umetnosti.

Za tokijske Neo-Dada-Organizatore umetnost je predstavljala produžetak života i svojevrsno „otkrovenje na đubrištu“ - njihovo igralište rođeno je na bespuću posleratnog Japana i u savremenoj urbanoj realnosti. Oni su otkrili jedan nov svet skrivenih kvaliteta u običnim, nenametljivim svakodnevnim predmetima. Nastavši u vreme kada i francuski pokret Novih realista (Nouveaux réalistes) - čedo kritičara Pjera Restanija (Pierre Restany) i slikara Iva Klajna (Ives Klein) - tokijski naodadaisti „otkrili“ su posebnu likovnu vrednost u prizorima masovnog otpada kao proizvoda hiperprodukcije materijalističkih vrednosti amerikanizovanih gradova u posleratnom industrijskom svetu. Obe grupe su pravdale svoj radikalni iskorak od apstraktnog slikarstva ka umetnosti asamblaža napravljanih od đubreta, pozivajući se na dadaističko nasleđe, preuzimajući istovremeno od nadrealista praksu aranžiranja pronađenih predmeta fragmentacijom, sučeljavanjem i nagomilavanjem. Za razliku od američkog pop-arta, koji je svoje polje delovanja pronašao u direktnoj banalnosti i komercijalnoj anonimnosti gradske realnosti, pripadnici pokreta novih realista i Neo-Dade tragali su za neprimetnom, začudnom prirodom svakodnevnih predmeta, starih i novih podjednako. Međutim, dok su pripadnici francuskog pokreta korišćenjem otpada nastojali da stvore objet d'art u svom završenom, tradicionalnom obliku, Neo-Dada-Organizatori koristili su đubre u procesu izvođenja performansa kao prolazne,„privremene manifestacije svoje svakodnevne realnosti“. Poput pokreta Gutai, tokijska Neo-Dada se oslanjala na proces fizičke interakcije tela i materijala, kao i na participaciju publike i medija u finaliziranju projekata. Upravo zbog ove sklonosti ka teatarskom praktikovanju umetničkog procesa „umetnosti zarad trenutka", u kojoj umetnički predmeti služe poput pozorišnih rekvizita - skoro ni 
jedan od prvobitnih radova Neo-Dade danas nije sačuvan u celosti, te ih mi danas uglavnom poznajemo sa fotografija.

Treća faza prelaska iz "modernog" u "savremeno", označila je, sa jedne strane, tendenciju u kojoj radovi preispituju fizički prostor galerije i mogućnosti izlaska iz nje, a sa druge, potrebu samih umetnika da svoju akciju iznesu na ulice. Šezdesetih godina, korišćenje masovnih medija štampe, filma i televizije - postalo je omiljeni način umetničkog delovanja, najčešće posredstvom fotografije. Umetnici su, između ostalog, stvarali pod snažnim uticajem prizora studentskih direktnih akcija tokom demonstracija protiv sporazuma Anpo, prenošenih preko televizije u domove širom Japana. Tokio ne samo da je postao poprište političkog prostesta (koji se u jednu ruku može shvatiti kao javni performans), taj grad je bio i veliko umetničko igralište. Umetnici su koristili javni prostor kao vlastiti forum za radikalne akcije i dešavanja. Ove "gerilske" akcije se mogu shvatiti kao reakcija na prostornu, topografsku i društvenu reorganizaciju Tokija, kao i na nedostatak gradskog infrastrukturnog prostora za umetnike i njihovo delovanje.

Tokijski umetnički kolektiv Hi Red Center, ostvario konceptualističku evoluciju anti-umetnosti svojom nenametljivom, tihom i suptilnom infiltracijom u socijalni prostor, predstavljajući most ka tzv. ne-umetnosti (hi-geiđucu) sa kraja šezdesetih godina. Jezgro kolektiva Hi Red, činile su tri značajne umetničke figure - Akasegava Genpei, Nakaniši Nascujuki i Takamacu Điro. Tokom samo osamnaest meseci postojanja, u periodu od 1963-64. godine, grupa je izvela seriju „intervencija“ u javnom prostoru. Ova tendencija HRC-a da uspostavi blisku interakciju s društvom, u kome ono postaje „materijal“ ili „platno“, najslikovitije je predstavljeno njihovim poslednjom akcijom, Projektom čišćenja, u kome je karakter zajedništva, oličen u "kolaborativnom pregnuću“, vešto upotrebljen kao oruđe socijalne kritike. Ovaj događaj, poznat takođe pod imenom „Kampanja za promociju higijene i reda u oblasti metropole“, odnosno „Budi čist!“, održana je usred urbane vreve, na ulicama Ginze u Tokiju, 16. oktobra 1964. godine. Tom prilikom su članovi grupe sa saradnicima paradirali obučeni u uniforme zdravstvenih radnika, sa naočarima za sunce i crvenom trakom na rukama, na kojoj je belom bojom bio ispisan zaštitni znak grupe - „!“. Oni su brižljivo i pedantno ribali pločnike, a povremeno i saobraćajne tra- 
ke, koristeći četkicu za zube, krpu za pod i drugo krajnje nedelotvorno oruđe za čišćenje velikih uličnih površina.

Ovaj „događaj čišćenja», održan sedmog dana Olimpijskih igara u Tokiju, predstavljao je direktno ismevanje ubrzanih napora gradskih vlasti da ulepšaju i modernizuju grad, kao i nastojanja japanske vlade da opravdaju naziv „ekonomskog čuda“ predstavljanjem sterilne vizije Japana kao ponosnog člana međunarodne zajednice. „Zvanične “ uniforme HRC-a - beli mantili i signalne table koje su nosili (na kojima je bilo napisano Sođi ću - čišćenje u toku) ispostavile su se kao savršen paravan za naizgled legitimnu i uobičajenu akciju usred belog dana. Prolaznici nisu bili svesni da se bilo šta neobično dešava, a njihovo ozbiljno držanje zavaralo je i policiju. Jedan policajac im je čak zahvalio na požrtvovanoj akciji za ulepšavanje grada. HRC je ovom, ali i prethodnim intervencijama, pokušao da razdrma dokonu dobrostojeću srednju klasu svojom kritikom uspavanog, inertnog i odveć predvidljivog mentaliteta, koji se upravo $u$ to vreme formirao pod birokratskom kontrolom državnog aparata. Nema sumnje da su aktvnosti HRC-a bile inspirisane idejom „direktne akcije“ i radikalnog aktivizma u vreme kada je japansko društvo uljuljkavano uspavankom novostečenog materijalnog blagostanja. Već i samo ime grupe - Hi Red Center (,Visoki crveni centar") - otkriva njihove levičarske tendencije: nastalo je od engleskog prevoda početnih ideograma njihovih prezimena: taka (visoko), aka (crveno), naka (centar).

HRC je ostvarivao blisku saradnju sa drugim kolektivima i pojedincima, poput improvizacione muzičke grupe Ongaku i umetnice Joko Ono. Upravo je ova šira grupa umetnika činila okosnicu japanske sekcije pokreta Fluxus, poznatog kao tokijski Fluxus. Događaj koji je Joko Ono organizovala u centru Sogecu 1962. godine, okupio je umetnike poput Akasegave i Jasunao Tonea, dok je hepening koji je najavio formiranje HRC-a - „Večera u spomen poraza u ratu"(Haisen kinen bansankai) - održan u avgustu 1962, zapravo predstavljao zajednički projekat Neo Dade, Grupe Ongaku, plesača kolektiva Ankoku Buto i Akasegave Genpeija. Tom prilikom posetioci su, u suštini, bili nasamareni: navedeni su da plate skupu ulaznicu za večeru u kojoj nisu mogli da učestvuju, a bilo im je omogućeno samo da gledaju dok su umetnici neumereno jeli, pili, igrali i prali zube.

Nekih dva meseca kasnije, u fazi neposredno pred osnivanje HRC-a, Nakaniši i Takamacu su izveli svojevrsni gerilski performans na kružnoj že- 
lezničkoj liniji Jamate (kasnije preimenovanoj u Jamanote), koja saobraća od Šinagave do Uena i povezuje velike tokijske gradske centre. Tokom ovog performansa, danas poznatog pod imenom „Incident sa Jamanote linije" (jamanote sen điken), umetnici su se vozili lica obojenih belom bojom, noseći neobične umetničke predmete i pauzirajući na stanicama kako bi izvodili ritualističke hepeninge, dramatizujući uskomešani prostor japanske svakodnevice svojom umetničkom kritikom i praksom. Nakaniši je, na primer, prolivao boju po peronu i lizao je, a zatim polomio jedan providni objet u obliku jajeta, u kome su se nalazili nasumično odabrani predmeti za svakodnevnu upotrebu: stari sat, ogledalo, kašika. Ovaj događaj je sasvim sigurno bio zamišljen kao satira haotične svakodnevnice kojoj su izloženi užurbani putnici na putu za posao.

Članovi grupe su se neretko podsmevali konvencionalnim galerijskim protokolima, što su na duhovit način i ostvarili primenujući obrnutu logiku u projektu ceremonije „zatvaranja“ jednonedeljne ne-izložbe u galeriji Naniqua u Tokiju, juna 1964. godine. Na pozivnicama za izložbu pod nazivom „Veliki panorama šou“ pisalo je: „Zatvaranje izložbe Hi Red Center je upravo u toku. Kada budete imali vremena, molim vas nemojte prisustvovati“. Akasegava i Nakaniši su otišli prvoga dana trajanja „izložbe“, zakucavši daske na ulaz galerije, na kojima je pisalo „zatvoreno“. Prostor su ostavili netaknut do poslednjeg dana, kada su održali ceremoniju „otvaranja“ kojoj su prisustvovali Takigući Šuzo, lćijanagi Toši, Sem Frensis i Džasper Džons, koji su im pomogli da izvade eksere iz dasaka. Čak su i pop-art radovi na izložbi bili bukvalno obrnuti, sa etiketama zalepljenim u unutrašnjosti konzervi. Prikazujući "obrnuti svet“, mondo inversus, njihova nadrealna parodija osporavala je zapravo sve što je bilo samo navika, predrasuda, društvena konvencija i moralno tutorstvo.

Karijera trojice osnivača HRC-a su se nakon prestanka rada kolektiva kretale u raličitim smerovima. Nakaniši se ponovo vratio slikanju, nastavljajući saradnju sa avangardnim muzičarima i plesačima. Takamacu je nastavio sa intelektualnim, analitičkim i razigranim pristupom umetnosti, započevši istraživanje realnosti i iluzije, odnosno konceptualnog razdora između percepcije i egzistencije kroz svoju seriju „Senki“ (Kage, 19651974). Ova uticajna serija radova, koja će incirati tzv. "debatu o senci“ među japanskom umetničkim kritikom, prikazuje (naslikanu) siluetu pred- 
meta na belom platnu, beležeći trag onoga što je odsutno. Godine 1968. počeo je da radi kao profesor na univerzitetu Tama biđucuu daigaku, gde će uticati na rađanje nove generacije konceptualnih umetnika sa kojom je nastavio saradnju u okviru pokreta Mona-ha i tzv. Škole metafizike. Akasegava Genpei se, razočaran nakon izgubljenog sudskog procesa vođenog protiv njega i njegove umetnosti, posvetio konceptu „ultra-umetnosti“ (ćo-geiđucu / Tomason), u kome fotografije običnih, besmislenih objekata iz urbane svakodnevice prezentuje kao konceptualna dela i umetničke predmete. Godine 1981, dobio je prestižnu književnu nagradu Akutagava za kratku priču koju je napisao pod pseudonimom Ocuđi Kacuhiko .

Osim Hi Red Centra, Akasegava Genpeija i grupe Bikjoto (Biđucuka kjoto kaigi), kojima se obično pripisuje namera da premoste "jaz" između politike i umetnosti, postojala je i radikalnija struja umetnika koja se najčešće naziva "ritualnom školom" (gišiki-ha). Njih je ujedinjavala sklonost ka povrtaku premodernoj mašti, kao što je to slučaj sa pozorišnim andergraund pokretom Angura engeki. U ovoj eri tzv. "kolaborativnog kolektivizma", umetničke kolektive je ujedinjavala fascinacija telom kao sredstvom iskazivanja samodegradacije i spektakla, kao i potreba za stvaranjem odgovarajuće opozicije u javnosti.

"Ritualna škola" (gišiki-ha) je termin kojim su obuhvaćeni oni umetnički kolektivi i pojedinci koji su tokom šezdesetih godina želeli da povrate izgubljeni osećaj humaniteta, suprotstavljajući se tehnokratskoj i korporacijskoj kontroli, sporovođenoj pod pozitivističkim izgovorom ekonomskog rasta, tehnološkog napretka i internacionalizacije. ${ }^{4}$ Videvši u sebi "harfiste buđenja", očišćenja, postajanja čovekom, ritualistički izvođači su često sa verom u večno ljudsko - pozajmljivali elemente svakodnevnog života i zabave premodernog Japana, koji su delimično bili odbačeni ili izgubljeni u procesu frenetične vesternizacije tokom perioda Meiđi, da bi dodatno bili potisnuti tokom šezdesetih godina kada je Japan prolazio kroz proces ubrzane urbanizacije i industrijalizacije.

Zero đigen ("Nulta dimenzija") je svakako bio najznačajniji i medijski najviše eksponiran kolektiv među "ritualistima", koji je vešto eksploataisao senzacionalističku i pornografsku prirodu žute štampe, jašući na talasu kontrakulturnog pokreta angure. Zero đigen je bio poznat po svojim

$4 \quad$ KuroDalaiJee, Performance Collectives in 1960s Japan: With a Focus on the "Ritual School". Positions, in: East Asia Cultures Critique, Volume 21, No. 2 (2013) : 427. 
"ritualima" (gišiki) izvođenim na javnim mestima - vozovima, grobljima, okupiranim univerzitetima - ali i u zatvorenom prostoru: u vodviljima, andrgraund pozorištima i klubovima. Njegovo grubo, iznenadno narušavanje urbane svakodnevnice ispoljavalo se kroz izrazito asocijalno ponašanje (poput valjanja po zemlji), upotrebu rekvizita (poput gas-maski) i golotinje, a sve u cilju razaranja konvencija prikladnog i moralnog ponašanja i šokiranja posmatrača. Rituali grupe Zero đigen su, s jedne strane, služili kao sredstvo privremenog povratka u preddruštveno stanje, a sa druge, imali su efekat sabotiranja propisane hijerarhije društvenih vrednosti. Nisu pritom predstavljali neki pojednostavljeni, naivni poziv na povratak primordijalnoj vitalnosti ili sasvim nepromišljeni antimoderni otpor. Oni su, zapravo, nastojali da se suprotstave kompleksnoj realnosti urbanog života u cilju otkrivanja kontradikcija modernog društva, čije sterilno naličje briše sećanja na krvavu istoriju i naivnu premodernu narodnu duhovnost.

Posmatrano iz šire perspektive, potreba "ritualista" da povrate izgubljeni Japan tumači se kao neka vrsta odgovora na opštu kulturnu klimu u japanskom društvu šezdesetih godina, kada su popularisani enka (muzički žanr nastao pod uticajem folklornih melodija) i rekiši šosecu ("istorijske novele"). Ova kolektivna nostalgija za drevnim običajima ogledala se na intelektualnom nivou u oživljenom interesovanju za etnološka istraživanja Janagita Kunia. U umetničkom kontekstu, taj isti duh je, na primer, prožimao pozorišni izraz Kara Đura, ikoničnog predstavnika angura (anderground) kulture koji je nastojao da povrati misemono (popularne spektakle) i daidogei (ulične predstave), koji su karakterisali popularnu zabavu Eda (premodernog Tokija). Fenomen avangardne nostalgije, svojevrsnog povratka premodernom, neprekidno je pratio i proces razvoja plesnog izraza buto, čiji su osnivači bili Tacumi Hiđikata i Ono Kazuo. Filmski reditelj Imamura Šohei takođe stvara fiktivni svet premodernog, vanvremenskog društva zasnovanog na šamanističkim verovanjima i planinskim bogovima iz Šinto mitologije, prerađujući nativističke tradicije koje su značajno prethodile japanskoj modernizaciji, kao nasleđu koje stoji skriveno ispod površine savremenog japanskog društva.

Sredinom šezdesetih, izvestan broj značajnih avangardnih umetnika napustio je Japan i preselio se u Evropu i Ameriku. Umetnice Šiomi Ćieko i Kubota Šigeko, preselile su se u SAD i pridružile pokretu Fluxus 1964. 
godine. Njujork se činio posebno privlačnim upravo zahvaljujući živim aktivnostima Fluxusa. Mnogi japanski umetnici videli su ovom pokretu ista ona načela koja su reflektovala njihovu osudu tradicionalnih umetničkih formi i uvreženih odnosa umetnosti i društva. Kustos Aleksandra Manro (Alexandra Munroe) je identifikovala čak 23 japanska umetnika koji su fizički, ili putem poštanske razmene, učestvovali u radu Fluxusa u periodu od 1961. godine do Macijunasove smrti (1978). ${ }^{5}$ Nijedan zapadnjački umetnički pokret nije u prethodnom periodu do te mere integrisao japanske umetnike u svoju aktivnost; nikada niti ostvario tako blisku saradnju sa umetničkim andergaundom u Tokiju. Internacionalizam je bio deo Fluxus strategije: prihvatajući Azijce u svoj zagrljaj, mogli su da prošire ograničenu geografiju evro-američkog modernizma kako bi proširili svoju anrho-socijalističku utopiju. Prisustvo japanskih umetnika takođe je reflektovalo interesovanja pripadnika grupe za azijsku filozofiju i estetiku - pre svega za taoizam i zen budizam, koji su popularisani u Americi zahvaljujući uticajnom delovanju Džona Kejdža.

Japanske pripadnice pokreta Fluxus su takođe zaslužne za promociju feminističkog diskursa u svojim performansima. Ovi feministički aspekti su ponekad bili dodatno problematizvani pitanjima rase i klasne pripadnosti, što se može videti na primeru Komada sa sečenjem („Cut piece“) autorke Joko Ono. Tokom ovog performansa, ona je nepomično sedela na pozornici u tradicinalnoj japanskoj ženskoj sedećoj pozi, sa makazama pokraj nje. Pojedinci iz publike su makazama sekli komad po komad njene odeće, dok nije ostala praktično gola, sa bazizražajnim, ukočenim licem. Šigeko Kubota je u svojem delu Slikanje vaginom („Vagina painting“) - izvedenom tokom „Perpetual Fluxfest“-a u Njujorku 1965. godine - zauzela aktivniju ulogu, dovodeći u pitanje zapadnjačke i japanske kanone umetničke prakse u kojima muškarci zauzimaju dominantnu poziciju. Zakačivši četkicu namočenu u kravavo crvenu boju za donji veš, slikala je u čučećem položaju po papiru na podu, evocirajući porođaj primitivnih žena. $U$ ovoj parodiji Polokovog mačističkog akcionog slikarstva, Kubota je izrazila agresivnu i primalnu prirodu potisnute ženske seksualnosti i telesnog bola. ${ }^{6}$

$5 \quad$ Alexandra Munroe, Alexandra Munroe, Japanese Art after 1945: Scream Against the Sky (NY: Harry N. Abrams, 1994), 218.

$6 \quad$ Midori Yoshimoto, Into Performance : Japanese Women Artists in New York (New Brunswick, NJ, USA: Rutgers University Press, 2005), 179. 
Kao što smo već napomenuli, sredinom šezdesetih, razvoj ekperimentalne umetničke prakse doveo je do nastanka koncepta ne-umetnosti, gde naglasak više nije bio na stvaranju u tradicionalnom smislu, već na ne-stvaranju. Čista fizikalnost i neposredno suočavanje dostigli su, prema opštem shvatanju, svoje vrhunsko vizuelno uobličenje u jednostavnim avangardnim konstrukcijama dvanaest postpolitičkih, postideoloških skulptora koji će postati poznati pod nazivom Mono-ha ("Škola stvari"). lako se sami nisu smatrali fromalnom grupom, niti ih je ujedinjavalo istovetno viđenje umetnosti, oni su zastupali isti cilj - umanjivanje uloge umetnika u stvaranju umetničkog dela i naglašavanje neposrednog susreta (deai) materijala i njihovog okruženja. Neinhibiranom vajarskom izrazu i upotrebi materijala sigurno je doprinelo i njihovo likovno obrazovanje. Naime, većina njih nije potekla iz vajarskih, već iz slikarskih ateljea univerziteta Tamabi sa početka šezdesetih godina. Poput ostalih minimalista, umetnici Mono-ha delovali su kao pasivni posrednici predstavljajući fizičke predmete namenjene promišljanju - u svom izvornom stanju: kakvi jesu (aru ga mama).

Međutim, za razliku od Dišana, koji se podsmevao umetničkim konvencijama predstavljajući svakodnevne predmete u galerijskom kontekstu - pa i samih anti-umetničkih obje-a koji su aproprijacijom transponovani u status estetskog objekta - umetnička dela grupe Mono-ha pozivala su na kontemplaciju nasumičnih odnosa između svakodnevnih materijala i njihovog okruženja, između ljudskog ili prirodnog. To je uistinu otkrilo dotad nepoznate dubine materijalnih i psihosocijalniih odnosa. Kritika modernosti našla je, naime, svoj stvarni koren u poimanju "relacije" (kankei) u praktikovanju umetnosti. Usredsredivši se na "susret" stvari (egzistencija), mesta (prostor) i posmatrača (svest), grupa Mono-ha je krenula od izrazito nezapadnjačke premise da je umetnik samo „posrednik slučajnih događaja u okviru šireg, kontinuiranog procesa." Na ovaj način, publika je bila uključujena u proces revizualizacije i redefinisanja veza između materijala i prostora u kome se nalaze.

Umetnički fenomen Mono-ha geografski se vezuje za područje Tokija u periodu od 1968. do ranih sedamdesetih godina, a bio je obeležen tendencijom umetnika da prikažu prolazne postavke sirovih i netretiranih prirodnih i industrijskih materijala - platna, ugljena, pamuka, prašine, ja- 
panskog papira, ulja, kanapa, kamenja, drvenih klada, staklenih površina, električnih sijalica, plastike, gume, sintetičkih jastuka i žice - često postavljenih direktno na pod ili tlo u cilju ostvarivanja ,interakcije“ sa arhitektonskim prostorom ili spoljašnjom sredinom. Mono-ha se izdvojio od ostalih pripadanika avangarde krajem šezdesetih svojim minimalističkim pozivanjem na "kontekst", odnosno poimanjem umetnosti kao fenomena u stvarnom vremenu i prostoru. Uopšteno govoreći, bilo je posvećen konkretnom više nego teoriji; zainteresovan za rad sa lokalnim materijalima a nezainteresovan za kontakte s internacionalnom avangardom. Trudeći se da očuvaju svoju apolitičnost, zauzeli su donekle nepopularnu poziciju u atmosferi političkih previranja s kraja šezdesetih godina.

Značaj pokreta Mono-ha mogao se naslutiti već oktobra 1968. godine, kada je Sekine Nobuo predstavio svoje epohalno delo pod imenom Iso - daići (Faza - zemlja) u parku Suma Rikju u Kobeu. Skulptura se satojala od dva dela - rupe duboke 2.7 metara, prečnika 2.2 metra, i vertikalnog valjka identičnih dimenzija i zapremine, napravljenog od mešavine masne gline i betona, postavljenog pored rupe. „Faza - zemlja“ je koncipirana kao evolutivna prostorna permutacija, iznoseći podzemne slojeve zemlje na videlo u obliku „negativa zemlje“. Značaj ovoga dela se ne ogleda u „stvaranju“ predmeta, već u jednostvanoj izolaciji i premeštanju onoga što je već fizički prisutno. Koristeći zemlju kao sredstvo i cilj, Sekine je ukazao na neraskidivu vezu materijala, procesa i okruženja, aktivirajući vreme i prostor kao koegzistirajuće entitete. ${ }^{7}$

$U$ očima drugog značajnog predstavnika škole Mono - umetnika, kritičara i filozofa Li Ufana (Lee U Fan) - „Faza-zemlja“ označila je revolucionarnu prekretnicu ukazavši na pojavu „nove strukture“. Otkrivajući „svet kakav jeste" omogućila je telesni "susret" subjekta (deaiša) sa fenomenom pojave i nestanka zemlje, tokom koga subjekt percipira sebe kao deo strukture (kozo) sveta. Koncept „susreta“ (deai) je za Lija bio od izuzetnog značaja i njega će teorijski uobličiti u uticajnom eseju iz 1970. godine, „U potrazi za susretom" (Deai o motomete), definišući ga kao momenat otkrovenja (satori) ili samozpoznaje, u kome nam se ukazuje živopisan svet izvan fenomenološke subjektivnosti. Ukazujući na neraskidive odnose, odnosno na međuzavisnost materije, konteksta, prostora i vremena, Li

7 Mika Yoshitake, Requiem for the Sun: The Art of Mono-ha (Los Angeles: Blum \& Poe, 2012), 97. 
koristi filolozofski pojam „relatum" (kankeiko - „faza odnosa“ ili „,relacionalnost"), što će 1972. godine postati naziv svih njegovih radova u trodimenzionalnom prostoru: kako prošlih, tako i budućih. Zato je „Relatum" iz 1971. godine bio predstavljen u obliku site-specific intalacije sastavljene od velikih kamenih gromada postavljenih na japanske zabuton jastuke, nudeći koncept totalnog iskustva kroz temporalnu i prostornu interakciju različitih elemenata: galerijskog prostora, osvetljenja i kretanja posmatrača kroz instalaciju. $U$ „,Relatumu“ iz 1969. godine, Li spušta veliki kamen na staklenu ploču postavljenu na pod, na kojoj izibijaju naprsline. Otkrivajući tenziju aktiviranu u momentu susreta dve materije, on transformiše naizgled proizvoljni, nasumični rezultat u umetničko delo.

Značaj pokreta Mono-ha uveliko nadilazi njegov kratak stvaralački vek i oskudno materijalno nasleđe, koje se - uslovljeno najpre efemernom prirodom njihovih umetničkih konstrukcija - umnogome oslanja na fotografsku dokumentaciju. Njihova originalnost, kao i promišljeno kreativno reinterpretiranje japanskih estetskih načela, otelovljenih u tihoj, kontemplativnoj atmosferi zen bašti ili akcijama pokreta Gutai, poništava brojne kritike koje su im upućene zbog previše cerebralnog, rezervisanog doživljaja umetnosti ili političke nezainteresovanosti. Ukidajući uvreženu stvaralačku hijererhiju u kojoj umetnik potčinjava materijal kako bi ga preoblikovao prema svom liku, Mono-ha je bar donekle povratio osećaj skrušenosti i poštovanja prema silama prirode, izgubljen u materijalističkoj, dehumanizovanoj industrijskoj realnosti XX veka.

U samom središtu značajnih grupnih projekata iz šezdesetih godina nalazio se i čuveni japanski fotograf Eiko Hosoe (Eikoh Hosoe, 1933-). Medijski obdaren, on je, poput genijalno razigranog odraslog deteta, postao primer uspešne saradnje sa gotovo svim značajnim predstavnicima umetnosti toga vremena. Pedesetih godina je bio član avangardne grupe Demokrato, ali je ubrzo osnovao Eksperimentalnu džez filmsku radionicu, u kojoj su snimani zapaženi filmovi koji su zastupali multimedijalnu ideju i negovali interdisciplinarnu notu.

Umetnost novih vizuelnih efekata mogla bi se, pojednostavljeno, podeliti na dva suprotstavljena tabora: na one koji propituju granice tela i one koje propituju granice i mogućnosti samog predstavljanja. U prve nesumnjivo spadaju kompulsivni efekti, destrukcija prerasuda i trajni procesi transgresije materijala. S razlogom se upućuje na mračnu, erotikom 
nabijenu seriju fotografija Hosoe Eika Ubijanje ružama (docniji podnaslov: Kažnjavanje ružama, Ordeal by roses, Bara-kei, 1963), u kojoj je zapravo protagonista bio slavni književnik Mišima Jukio. Objavljena prvo u Tokiju, 1961-62, serija je snimana u Mišiminom domu uređenom u rokoko stilu, predstavljajući Mišimu kao bizarnog bodibildera obučenog u jednostavan japanski fudonši (tradicionalno donje rublje, parče tkanine oko kukova). Ova snolika vizija muškog tela i homoerotskog zanosa odslikava Mišimino interesovanje za granične, alternativne oblasti seksualne psihologije i prakse, ali u isti mah glorifikuje i ideju smrti, nagoveštavajući u zlokobnom smislu Mišimin tragični kraj.

Hosoe je u više navrata sarađivao sa Tatsumi Hiđikatom, začetnikom avangardnog plesnog tetra ankoku -buto. Jedan od plodova njihove saradnje bila je i fantastična serija fotografija pod nazivom Kamaitaći („Srpasta lasica"). Kao album slika o šumskom duhu iz sveta bajki njegovog detinjstva, Kamaitaći je 1969. godine štampan kao knjiga. Uzevši, međutim, kao polazište japansku premodernu maštu i reagujući na period izuzetnog previranja u japanskom društvu, Hiđikata i Hosoe su ispitivali mogućnost stvaranja umetničkog otpora modernizmu, materijalizmu i evropskom humanizmu, smatrajući da se u današnjem globalnom selu, zahvaljujući „zbližavanju“ publike i medija, oblikovao otuđen pogled na svet. Kao probuđeni jednoličnim zvukom tradicionalnih japanskih instrumenata i sjedinjeni sećanjima na odrastanje u japanskoj provinciji tokom rata, zaputili su se u svet drevnih duhova i demona regije Tōhoku, odakle su obojica ponikli - kao, uostalom, i neki drugi značajni avangardni umetnici toga vremena, poput Ona i Terajame.

Iz duboko zapretanih i već zaboravljenih kutaka kolektivnog sećanja, najednom se počelo uobličavati nešto sasvim novo, a u isti mah snagom emocija tako duboko ukorenjeno u predačku tradiciju. U duhu Prustovog „stvaralačog sećanja“, autori su simultano povezali različite vremenske ravni u rizomski razgranatu narativnu strukturu, najavljujući strategije koje će postati raširena odlika i poezije i proze našeg vremena. Tokom tri godine rada na projektu, Hiđikata i Hosoe su se više puta vraćali u Hiđikatin rodni kraj u prefekturi Akita. Na njima je zabeležen Hiđikatin performans kao spontana interakcija sa okolnim pejsažom i ljudima koje su slučajno sretali. Tako ga možemo videti kako skače preko polja poput nekog vilenja- 
ka i viri preko ramena seoskih starica prisluškujući njihov razgovor, kako juri preko polja s odojčetom u ruci ili kako čuči na seoskoj ogradi poput ptice. Na pojedinim slikama deluje kao zamrznut usred skoka, naglašavajući „začudnu temporalnost“ fotografije.

Krajem šezdesetih godina minulog veka, neodadaizam je počeo da zamire. Dematerijalizaciju umetnosti pratila je promena umetnička prakse - umetnički objet ubrzo je zamenjen instalacijama, konceptualizmom i performansima. Treba istaći da se termin performans odnosi na one izvedbene prakse vizuelnih umetnika koje ne potpadaju pod ustanovljene žanrove izvedbene umetnosti (pozorište, ples, muzika). Pojmovi "performans" (pafomansu) ili "umetnost performansa" nisu bili prisutni u Japanu sve do osamdesetih godina. Umetnici su za svoje intervencije upotrebljavali termine "ritual" (gišiki), "hepening" (hapuningu), "događaj" (ivento), "akcija" (akušon ili koi). Već početkom sedamdesetih, većina avangardnih umetnika koji su imali vodeću ulogu u posleratnom periodu udaljila se od kolaborativnih projekta i započela sa individualnom umetničkom praksom, osvajajući jednu potpuno novu teritoriju umetničke produkcije/recepcije pomeranjem fokusa sa problema kreacije na problem percepcije materije kao takve.

lako još nije došlo do eksplicitnog mapiranja ovih problema, jedan drugi fenomen iz oblasti estetike recepcije sa krajnje neobičnom stapanjem „horizonta očekivanja“ privukao je veliku pažnju. $U$ isto vreme, naime, obnovljeno interesovanje za azijsku umetnost i zen budizam u Severnoj Americi doprineli su stvaranju minimalizma, obnavljanju smisla za simetriju, ambijentalnu uravnoteženost, doslednu svrsishodnost, što je povratno uticalo na japanske umetnike. Interesovanje za strukturalno poimanje mogućnosti kamere i procesa snimanja kod Amerikanaca koincidiralo je sa željom japanskih umetnika da se vrate čisto estetskim temama. lako je, prema opšteprihvaćenom mišljenju, pokret minimalizma ponikao u Severnoj Americi, moramo ponoviti da su njegovi postulati bili sasvim bliski japanskim umetničkom senzibilitetu koji oduvek vrednuje apstraktne kvalitete materijala i ogoljenu formu. Filmove nove generacije obeležilo je vraćanje intimnom - stanje bivstvovanja odnelo je primat nad željom za akcijom u okvirima novog, strukturalno-materijalističkog filma. $U$ fokus interesovanja došlo je istraživanje umetničkih procesa: filmska 
emulzija služila je kao materijal na kome se crta ili grebe, filmski kadar je tretiran kao polje boje nalik pejsažu, film je doživljen kao smena kadrova ili statičnih fotografija.

Tako nas "Magla" (Kiri, 1971), rad umetnika Hagivara Sakumija, uvodi u svoju kontempletativnu crno-belu dimenziju usporenog vremena slikama koje podsećaju na niz monohromnih pejsaža rađenih u tušu. Njegova interesovanja za delikatne prirodne promene deli i Jamazaki Hiroši. U delu "Heligrafija" (1975), on kamerom beleži pokret zimskog sunca tokom perioda od trideset dana, vizualizujući proces koji ne može biti zabeležen ljudskim okom.

Međutim, jedno remek-delo kinematografskog strukturalizma potvrđuje tezu da je umetnost definitivno odbacila slikanje objektivnog sveta; da se, u suštini, okrenula samoj sebi i procenjivanju svoje sopstvene uloge i moći. Kako je samo daleko ostalo za nama upozorenje Džordža Santajane iz knjige The Life of Reason (1905/06), koji je rekao da "ništa nije tako siromašno i melanholično kao umetnost koja je zainteresovana samo za sebe, a ne za svoj predmet". Reč je, razume se, o tehnički izuzetno zahtevnom projektu Macumoto Tošia pod imenom Atman (1975). U ovom brižljivo konstruisanom filmu, nazvanom po staroj sanskritskoj reči za sopstvo ili dušu, vidimo čoveka u No kostimu sa glavom đavola koga kamera beleži kružnim pokretom, frejm po frejm, iz čak 480 pozicija. Naizmenično prikazujući krupni plan lica i bočni plan pokretima zum-objektiva, Macumoto postepeno ubrzava tempo filma i vizuelnim zasićenjem dovodi gledaoca na korak do psihodelične opijenosti.

Ne treba zaboraviti ni očiglednu, nažalost često prenebregnutu, činjenicu da su nezavisni kinematografi često samo mehanički mešali fikciju i stvarnost u svojim ostvarenjima, unoseći „inserte“ - inkorporirajući tematske žurnalističke materijale poznatih savremenih medijskih događaja. U svojim ekperimentalnim filmovima Macumoto Tošio uzdiže ovu praksu na znatno viši nivo primenom svojevrsnog "sinematskog lukavstva", kako bi razotkrio konstitutivnu teatralnost samog žurnalizma. Primera radi, u filmu Za moje oštećeno desno oko (Cuburekakata migime no tame ni, 1968) koristi format podeljenog ekrana kako bi imitirao vizuelni format novina. Time upečatljivo simulira heterogenost i simultanost informacija o događajima koji se istovremeno prezentuju na novinskoj strani. Svesno 
izbegavajući koherentni narativ, Macumoto gledaočevu razmaženu percepciju „bombarduje“ beskrajnim nizanjem slika i zvukova kao iskidanih, međusobno nepovezanih fragmenata medijskih informacija koje su obeležile turbulentnu 1968. godinu.

Postoji više razloga zašto se izložba Expo '70, održana u Osaki pod malo banalnim nazivom "Progres i harmonija za ljudski rod", može smatrati za prekretnicu u posleratnoj japanskoj umetnosti. Sponzorstvo multinacionalnih kompanija (poput Pepsija i Sonija), koje je realizovano u još uzavreloj atmosferi antiameričkih demonstracija, nagnalo je mnoge umetnike i kritičare da izložbu Expo proglase neumitnim krajem japanske andergaund scene. Za njih je ovaj događaj predstavljao konačni zaokret ka komercijalizaciji umetnosti i trijumf tehnologije nad kulturom - tačnije, videli su proslavu njene dominacije nad japanskom tradicijom. U njihovim očima, on je jasno upozoravao na skrivenu integraciju kulture i umetnosti, na nevidljivu mrežu moći koja autorima dopušta samo poziciju diskretnog i doziranog prisustva u društvu. Sa duge strane, ne može se poreći da je izložba Expo '70 imala izuzetan značaj u pomeranju tehnoloških granica, pružajući mogućnost umetnicima i korporacijama da prikažu najnovija audiovizuelna dostignuća u svojevrsnoj utopijsko-futurističkoj atmosferi. Najbolji primer za to možemo naći u radu umetnice Fuđiko Nakaja - svojevrsnoj skulpturi od magle koja je okruživala futurističku geodetsku kupolu Pepsi pavljona - projektovanog od strane pripadnika međunarodne umetničko-inženjerske grupe E.A.T (Eksperimenti u umetnosti i tehnologiji).

Čini se da je sve aktuelnije bivalo i Benjaminovo teorijsko predviđanje istorijske sudbine umetnosti, kako je ubedljivo obrazloženo u njegovom često citiranom delu Umetnost u doba njene tehničke reproduktivnosti (1935). Kada je korporacija Soni sredinom šezdesetih godina prošlog veka na tržište izbacila prvu prenosnu video opremu, započeo je period intenzivnog eksperimentisanja u oblasti umetnosti videa. Komercijalizacija kulture nije nepovoljno uticala na razvoj video umetnosti, naprotiv - njeno vreme je zapravo tek počinjalo. Mnogi video kolektivi iz sedamdesetih neprekidno su privlačili brojne stvaraoce, okupljali ih svojim različitim vizijama i vokacijama - od disidentski nastrojenih studenata umetnosti koji su formirali video kooperative do kablovskih programera koji su žudeli da stvore alternativnu javnu televiziju. Popularna kultura će u 
narednim decenijama takođe značajno doprineti razvoju digitalne umetnosti - japanski muzički sastavi poput Plastics i Yellow Magic Orchestra uspešno su inkorporirali mašine, semplere i sintisajzere u svoje stvaralaštvo.

Ukrštanje savremenosti i urbisa, gusta isprepletenost gradskih ulica, pozorišta i filmskog platna - to je učinak onog mapiranja što je šezdesetih i početkom sedamdesetih godina minulog veka odlikovalo japansku avangardu. Međutim, moćni japanski filmski eksperiment, kao vrsta neprekidne provere u umetničkoj i profesionalnoj praksi, onaj aktivistički oblik kolektivne proizvodnje kinematografije, zamenjen je sasvim autorskim, artističkim pristupom pravljenju filma. Lišeni podsticajnog dijaloga i produktivnog previranja, blede i jenjavaju oni smeli iskoraci ka graničnim poljima medija, čime kinematografija dospeva u sferu tzv. „privatnog filma“ (kođin eiga), koji analizira ličnu, intimnu viziju autora.

Gledajući iz istorijske perspektive, uočava se da je proliferacija raznorodnih umetničkih stretegija tokom sedamdesetih uzrokovala pojavu paradoksa koji i danas karakteriše japanski umetnički svet - naime, što je umetnost postajala raznovrsnija, to se i društvo sve više integrisalo. Avangarda (zen'ei), koja je do tada funkcionisala na obodima umetničkog sveta, pripitomljena i "malokrvna" u očima aktivista, dospela je u okrilje onoga što se i danas u Japanu naziva "savremenom umetnošću" (gendai biđucu). Vizuelni i znakovni jezik davao je sve manje prostora eksperimentu; slike s ekrana će narednih godina sve više biti vremenski i prostorno odvojene od sveta koji ih okružuje, povlačeći se u ograđene prostore muzeja ili galerija.

\section{Literatura}

Bürger, Peter. "Avant-Garde and Neo-Avant-Garde: An Attempt to Answer Certain Critics of Theory of the Avant-Garde," New Literary History 41.4 (Autumn 2010): 695-715.

Chong, Doryun, ed. From Postwar to Postmodern: Art in Japan 1945-1989 : Primary Documents. New York: Museum of Modern Art, 2012.

KuroDalaiJee, Performance Collectives in 1960s Japan: With a Focus on the "Ritual School". Positions, in: East Asia Cultures Critique, Volume 21, No. 2 (2013) : 417-447.

Munroe, Alexandra. Japanese art after 1945: scream against the sky, New York: H.N. Abrams, 1994.

Tomii, Reiko. "After the 'Descent to the Everyday: Japanese Collectivism from Hi Red Center to The Play, 1964-1973, in: Collectivism After Modernism: The Art of 
Social Imagination after 1945, ed. Blake Stimson, 45-75. Minneapolis, MN, USA: University of Minnesota Press, 2007.

Yoshimoto, Midori. Into Performance : Japanese Women Artists in New York. New Brunswick, NJ, USA: Rutgers University Press, 2005.

Yoshitake, Mika. Requiem for the Sun: The Art of Mono-ha. Los Angeles: Blum \& Poe, 2012.

\section{Marko Grubačić \\ Ljiljana Marković \\ University of Belgrade \\ Faculty of Philology}

\section{THE EMERGENCE AND DEVELOPMENT OF MULTIMEDIA AND DIGITAL ARTS IN JAPAN}

\section{Summary}

The emergence of internet has undoubtedly contributed to the democratization and pluralism of artistic expression. This ubiquitous, easily accessible "virtual museum" has generated a new, internationally recognized generation of Japanese artists who successfully create artwork at the intersection of software programming, design and art. Unsurprisingly, visual arts have for some time ceased to exist in the exclusive realm of traditional, academically trained fine artists. Furthermore, presently, it seems that conversance with programming codes and information literacy are being imposed as requirements for successful creation and comprehension of technologically inspired art. On the other hand, confronted with a galimatias of visual information, we are increasingly struggling to recognize a genuine and lasting quality in artwork presented to us. By examining the circumstances that have instigated the emergence and evolution of multimedia and digital arts scene in Japan - a technological paradise of sorts where experimental art practices continuously find fertile ground - we might facilitate a deeper understanding of present global trends and future prospects of art practices that stand at the crossroad of art and technology.

Key words: Japanese culture, digital and multimedia art, art and technology 